\author{
Matthias Haenggi \\ Stephan M. Jakob \\ Jukka Takala
}

\section{Sedation level and prevalence of delirium: response to Brummel and Ely}

Accepted: 28 August 2013

Published online: 6 September 2013

(C) Springer-Verlag Berlin Heidelberg and ESICM 2013

This reply refers to the comment available at: doi:10.1007/s00134-013-3083-9.

Dear Editor,

We thank Dr. Brummel and his team [1] for their interest in our paper [2]. We agree that the prevalence of delirium in awake ICU patients in our study is similar to that found in earlier studies $(42.5 \%$ in the study by Ely et al. [3], $31 \%$ in our study). However, we propose that reports on delirium should be stratified for a sedation score during the assessment, because the apparent prevalence of delirium is dependent on how a depressed level of consciousness after sedation stop is interpreted. For instance, of 471 daily evaluations completed during the study by Ely et al. [3], a diagnosis by the reference standard of delirium was made in $25.2 \%$, stupor in $21.3 \%$, and coma in $28.5 \%$ of all observations. Yet, the authors report that delirium occurred in $83.3 \%$ of their patients. Unfortunately, in the validation studies neither CAM-ICU nor ICDSC described how sedated patients were handled.

The new DSM-V criteria for delirium published recently indicate that non-comatose patients with a reduced level of arousal of acute onset should be classified as having severe inattention and cognitive change, and hence delirium. We agree that such patients can be delirious. Nevertheless, it should be noted that the same criteria-which correspond to a RASS-2/-3 level-can also apply for sedated healthy volunteers, and patients with uneventful postoperative course during awakening from anesthesia.

By no means do we suggest that delirium should not be considered in sedated patients. However, we question the specificity of the assessments tools CAM-ICU and ICDSC in sedated patients who cannot hold eye contact for $10 \mathrm{~s}$. In contrast to what has been proposed for the CAM-ICU [4], we suggest to use the delirium assessment tools after sedation stop, and to indicate the level of consciousness during the assessment. An exclusive diagnosis of delirium is impossible before effects of sedation are ruled out. Regular sedation stops have been proven to improve outcome and reduce resource use.

We should make every effort not to miss a diagnosis of delirium. At the same time, misdiagnosing persistent sedation as delirium is dangerous as well: a recent delirium trial was prematurely stopped because of increased mortality in the treatment group [5]. In this study, almost $40 \%$ of the included patients had a negative RASS, half of them a RASS of -2 . In our view, sedation should be managed with a protocolized approach including a sedation goal and frequent assessments, and not with a delirium screening tool.

Conflicts of interest The Department of Intensive Care Medicine, Bern University Hospital has, or has had in the past, research contracts with Abbott Nutrition International, B. Braun Medical AG, CSEM SA, Edwards Lifesciences Services $\mathrm{GmbH}$, Kenta Biotech Ltd, Maquet Critical Care $\mathrm{AB}$, Omnicare Clinical Research AG, and Orion Pharma; and research and development/consulting contracts with Edwards Lifesciences SA, Maquet Critical Care AB, and Nestlé. The money is/was paid into a departmental fund; neither MH nor SMJ or JT have received any personal financial gain. The department has received unrestricted educational grants from the following organizations for organizing a quarterly postgraduate educational symposium, the Berner Forum for Intensive Care: Fresenius Kabi, GlaxoSmithKline, Merck Sharp \& Dohme, Lilly, Baxter, Astellas, AstraZeneca, B. Braun, CSL Behring, Maquet, Novartis, Covidien, Mycomed, and RobaPharma.

\section{References}

1. Brummel NE, Ely EW (2013) Sedation level and the prevalence of delirium. Intensive Care Med. doi: 10.1007/s00134-013-3083-9

2. Haenggi M, Blum S, Brechbuehl R, Brunello A, Jakob SM, Takala J (2013) Effect of sedation level on the prevalence of delirium when assessed with CAMICU and ICDSC. Intensive Care Med. doi:10.1007/s00134-013-3034-5

3. Ely EW, Inouye SK, Bernard GR, Gordon S, Francis J, May L, Truman B, Speroff T, Gautam S, Margolin R, Hart RP, Dittus R (2001) Delirium in mechanically ventilated patients: validity and reliability of the confusion assessment method for the intensive care unit (CAM-ICU). JAMA 286:2703-2710. doi:11730446

4. Ely EW (2010) Confusion assessment method for the ICU (CAM-ICU) The complete training manual. http://www.mc.vanderbilt.edu/ icudelirium/docs/

CAM_ICU_training.pdf. Accessed 15 Mar 2013

5. van Eijk MM, Roes KC, Honing ML, Kuiper MA, Karakus A, van der Jagt M, Spronk PE, van Gool WA, van der Mast RC, Kesecioglu J, Slooter AJ (2010) Effect of rivastigmine as an adjunct to usual care with haloperidol on duration of delirium and mortality in critically ill patients: a multicentre, double-blind, placebo-controlled randomised trial. Lancet 376:1829-1837

M. Haenggi ( $)$ - S. M. Jakob - J. Takala Department of Intensive Care Medicine, Bern University Hospital, Inselspital,

Bern, Switzerland

e-mail: matthias.haenggi@insel.ch

Tel.: +41-31-6323029 